\title{
Escuchar el grito de las víctimas Impulsos desde la teología de la liberación
}

\author{
Jaime Comabella Callizo, F.M.S. \\ Benjamin Jonathan Schwab \\ Martha Zechmeister, C.J. \\ Departamento de Teología \\ San Salvador, El Salvador.
}

Este artículo recoge los primeros resultados del proyecto de investigación teológica, realizado por la Maestría en Teología Latinoamericana de la Universidad Centroamericana "José Simeón Cañas" (UCA), titulado "Reconciliación a partir de las víctimas. Impulsos desde la teología de la liberación en medio de una realidad de muerte". El proyecto, desde su inicio, en octubre de 2016, se ha acercado al drama de las víctimas de la violencia actual en El Salvador para, desde ahí, trazar los caminos de una posible reconciliación. Fieles a la tradición teológica de Ignacio Ellacuría, Jon Sobrino y tantos otros teólogos y teólogas de la UCA, tratamos de analizar de manera crítica la realidad histórica, denunciamos el escándalo de la violencia y mostramos pequeñas señales de vida y esperanza, que apuntan con fuerza hacia una sociedad más justa y más humana.

El Salvador forma parte del conocido triángulo norte centroamericano, conformado por tres de las sociedades más violentas del mundo: Honduras, Guatemala y El Salvador. Dentro de este consorcio, El Salvador se destaca por ser el país más violento de los tres. Según el informe del International Crisis

1. El equipo de investigación está integrado por Rodolfo Cardenal, Martha Zechmeister, C.J., Benjamin Jonathan Schwab, Jaime Comabella Callizo, F.M.S., José Arturo Mora Hernández, Herbert Galeano Funes, Andrea Mabel Rivas Córdova, Rodrigo Javier Recinos Alfaro y Luis Carlos Lozano Canales. 
Group $^{2}$, El Salvador ha superado a todos los países afectados por conflictos armados, excepto Siria. En 2016, la tasa de homicidios ascendió a 81 por cada cien mil habitantes ${ }^{3}$.

Nos hemos acercado a la realidad de las víctimas de esa violencia para explorar una práctica teológica que realmente pueda ser buena noticia para ellas y los pobres de El Salvador. Para ello, hemos entrevistado, en tres sesiones, a quince víctimas de la violencia.

Se trata de una investigación cualitativa que, en vez de arrojar cifras y datos estadísticos, busca explorar y comprender el sentir y las aspiraciones de esas personas. Por eso, las víctimas entrevistadas representan solo una pequeña muestra de una sociedad que lleva consigo el peso del sufrimiento, causado por la violencia desmedida, visible en las calles, las colonias, los cantones y las poblaciones del país. A pesar de esta limitación, ellas constituyen una muestra real y concreta. Son quince personas que, con sus historias y vidas de victimización, nos ayudan a aterrizar en lo real y nos ofrecen luces de vida y de esperanza.

Entre las personas entrevistadas, se encuentran jóvenes, que residen en zonas peligrosas y han sido acosados por las maras; familias que han debido huir de sus casas, inesperada y forzosamente; mujeres violadas y vejadas por el simple hecho de ser mujeres; personas pobres, que viven en hogares desestructurados o destrozados; personas violentadas por el Estado, el ejército o la policía; personas marginadas y amenazadas por su condición sexual. En definitiva, hombres y mujeres que han sufrido en carne propia el acoso, la extorsión, la violación, el asesinato de algún ser querido o la privación de sus derechos más fundamentales. De sus vidas, luchas y esperanzas, surgen las reflexiones que ahora ofrecemos.

\section{Teología a partir de las víctimas}

En la presentación del proyecto en la UCA, Rodolfo Cardenal lanzó al público asistente la siguiente pregunta: "¿qué tiene que ver la teología con el tema de las pandillas y la violencia?". Él mismo dio la respuesta: "tiene mucho que ver, porque parte de la realidad que estamos viviendo". En este primer apartado, vamos a presentar qué entendemos por teología, es decir, cuál consideramos que debe ser el quehacer de todo teólogo o teóloga, y cuál debe ser el método a seguir para hacer una teología próxima al evangelio.

2. Cfr. International Crisis Group, El salario del miedo: maras, violencia y extorsión en Centroamérica. Informe sobre América Latina $N^{\circ} 62$ (Bruselas: International Crisis Group, 2017).

3. La Organización Mundial de la Salud (OMS) considera epidemia cuando en un país hay más de diez homicidios por cada cien mil habitantes. 


\subsection{El legado de los mártires}

En la cercanía inmediata de nuestras oficinas y aulas se encuentra el Jardín de las Rosas, el lugar donde mataron a Ignacio Ellacuría y sus compañeros. Ese lugar habla con mucha fuerza sobre lo que es hacer teología. Ese lugar es, para el equipo que realizamos esta investigación, tierra santa, así como lo es todo El Salvador, consagrado por la sangre de sus mártires, entre los que se encuentran Mons. Romero y Rutilio Grande. En ellos se hizo presente o se historizó, como diría Ignacio Ellacuría, el drama de Jesús. Los mártires se pusieron de manera incondicional al lado de las víctimas y así desenmascararon a los poderes que dan muerte. Ellos provocaron la rabia de los victimarios y por eso fueron aniquilados por aquellos a los que señalaron. En los mártires salvadoreños nos encontramos con la presencia real del misterio de la crucifixión y la resurrección de Jesús, el misterio central de nuestra fe.

A este misterio, que ellos vivieron y sellaron con su sangre, le corresponde un lenguaje teológico de un vigor excepcional. Con Rutilio Grande, Mons. Romero e Ignacio Ellacuría irrumpió un nuevo modo de anunciar el evangelio y de denunciar el pecado en la Iglesia salvadoreña. Este nuevo modo de hablar, rechaza rotundamente el "docetismo" teológico y pastoral, la palabrería sin carne y vacía de realidad. En este nuevo lenguaje se encarna "la palabra viva y eficaz de Dios, y más cortante que espada de dos filos" ( $\mathrm{Hb} 4,12)$. Esa palabra crea realidad, es "liberadora y salvadora, como el lenguaje del mismo Jesús".

El concepto fundamental de la teología que nace de los mártires es el pueblo crucificado. De una manera audaz, identifica los sufrimientos del pueblo, expuesto a todas las crueldades posibles, con la cruz de Jesús. El pueblo entendió y "canonizó" ese modo de hablar. Lo reconoció de una manera inequívoca e inmediata: "ellos hablan de nosotros". El lenguaje de Rutilio, Romero y Ellacuría llegó sin rodeos a los corazones de los más vulnerables, otorgando al pueblo sufriente una dignidad última y teologal, que lo hacía sujeto de su propia historia.

\subsection{El peligro de dilapidar este legado}

Este legado es caro, porque costó la vida de muchas personas buenas. Sin embargo, existe la posibilidad real de dilapidarlo. En efecto, las dinámicas creadas alrededor de la beatificación de Mons. Romero pusieron de manifiesto este peligro de desperdiciar su legado por la exageración y la instrumentalización, motivadas por intereses eclesiales y políticos. Es peligroso que el presidente salvadoreño comparezca en Casa Presidencial con un cuadro gigante de Mons. Romero a sus espaldas, para ocultar detrás de él la política asesina de su

4. D. Bonhoeffer, Resistencia y sumisión. Cartas y apuntes desde el cautiverio, p. 161 (Salamanca: Ediciones Sígueme, 2008). 
gobierno. Las medidas extraordinarias de seguridad, propuestas por el presidente y aprobadas por la Asamblea Legislativa, legalizan la opresión feroz de la población que vive en la marginalidad y abren la puerta a todo tipo de aberraciones, como la tortura, las desapariciones y las ejecuciones extrajudiciales, en una palabra, el linchamiento de presuntos pandilleros. La mayoría pobre y excluida no se siente protegida por estas medidas, al contrario, percibe el abandono y la traición de todos los grupos políticos, sean de derecha o de izquierda.

Con nuestra investigación, nos incorporamos gozosamente a la tradición del Departamento de Teología de la Universidad Centroamericana "José Simeón Cañas" y damos continuidad a la teología de los mártires, conocida en todo el mundo por los principios que rigen su modo de hacer teología. Entre esos principios se destaca, en primer lugar, la "honradez con lo real"s. Ese modo de hacer teología se niega a ignorar y a prescindir de la realidad que perjudica a las víctimas. En segundo lugar, reconocemos como tarea teológica principal anunciar el "Dios de la vida", es decir, proclamar con todas las fuerzas humanas disponibles la gloria de Dios, que se concreta en la lucha a favor de la vida de los más vulnerables y de las víctimas.

Esta tarea demanda un verdadero vigor académico, pero nunca es una labor meramente intelectual. Hacer teología tras las huellas de los mártires exige hacernos seguidores y seguidoras de su praxis, que no es, ni más ni menos, que la praxis de Jesús. Quien quiera hacer teología en la tradición de Óscar Romero y de Ignacio Ellacuría, ha de comprometerse a hacer lo que ellos hicieron. La metáfora de Dietrich Bonhoeffer, el gran mártir de la Iglesia luterana en los tiempos del régimen nazi, nos invita a lanzarnos contra los radios de la rueda, el bárbaro instrumento de tortura y ejecución medieval, para detenerla con nuestros cuerpos. En la actualidad, la rueda es la maquinaria que sigue triturando víctimas.

Ignacio Ellacuría da la pauta sobre lo que significa actualizar este modo de hacer teología: "Actualizarlo no significa primariamente ponerlo al día, al menos en el sentido que esta expresión puede tener de estar a la moda de los tiempos. Actualizarlo significa, más bien, dar realidad actual..."'. El esfuerzo teórico académico para conocer los conceptos filosóficos y teológicos de la generación de los mártires nos exige, simultáneamente, "dar realidad" a su praxis aquí y ahora. La clave hermenéutica decisiva que abre el acceso a su pensamiento

5. J. Sobrino, "Espiritualidad y seguimiento de Jesús", en Mysterium Liberationis. Conceptos fundamentales de la teología de la liberación, vol. II, p. 453 (Madrid: Trotta, 1990).

6. J. Sobrino, "Dios de vida e ídolos de muerte", en Jesucristo liberador. Lectura histórico-teológica de Jesús de Nazaret, p. 355 (San Salvador: UCA Editores, 2013).

7. I. Ellacuría, "Utopía y profetismo", en Mysterium Liberationis, op. cit., vol. I, p. 398. 
consiste en sintonizar con su modo de proceder. El esfuerzo intelectual se vuelve ciego cuando no está iluminado por la praxis martirial, es decir, la praxis de Jesús. La fertilidad teológica solamente puede brotar desde esa praxis.

La segunda indicación de Ellacuría, clave para esta investigación, es que entre los "signos de los tiempos" que hay que escrutar, como nos dice el concilio Vaticano II, hay uno principal: "Ese signo es siempre el pueblo históricamente crucificado, que junta a su permanencia la siempre distinta forma histórica de su crucifixión"8. Es una paradoja triste: el desafío más actual y urgente en cualquier tiempo siempre es el pueblo crucificado. Ese "siempre" no tiene nada que ver con una verdad eterna metafísica, sino que indica la actualidad escandalosa del pueblo crucificado en la historia. Cualquier intento por habituarse ante este escándalo, de acomodarse a lo inevitable, es cinismo. Y el "siempre lo mismo" contrasta con la variedad de formas de crucifixión del pueblo, siempre nuevas. ¡El pecado del mundo es muy creativo!

En consecuencia, no basta constatar la existencia permanente del pueblo crucificado, sino que hay que movilizar, siempre de nuevo, todas las energías intelectuales disponibles para analizar las dinámicas y los círculos viciosos del pecado estructural. Solo se comprende en qué consisten esos poderes que dan muerte a tantos seres humanos, cuando se tiene el valor de ir hasta el fondo.

\subsection{El método para hacer teología tras las huellas de los mártires}

La teología seria comienza con un acto de contemplación, con la mística de los ojos abiertos. Comienza con el valor de mirar con atención, de no cerrar los ojos ante estas realidades, que estimulan el instinto natural de mirar hacia otro lado lo más rápido posible. Comienza con resistir a la tentación del "no ver" la realidad de las víctimas de la violencia actual, que parece la negación feroz de un Dios bueno y misericordioso. Este "ver", este acto de contemplación, es un permitir dejarnos penetrar por el dolor de las víctimas. "Quien dice 'Dios', asume la vulneración de las propias certezas a resultas de la desgracia de los demás"”.

El lenguaje de Óscar Romero e Ignacio Ellacuría llegaba inmediata y vigorosamente a los corazones de las víctimas, en gran parte, por su capacidad para "ver". Sin ese acto de contemplación como principio de cualquier quehacer teológico, el lenguaje se convierte muy fácilmente en una palabrería piadosa. Las palabras más santas de esta tradición, como "el pueblo crucificado", pueden estropearse por abusar de su uso y por la verborrea. El lenguaje teológico solamente tiene valor y significado si, de nuevo, nace del dolor, del sentir con las víctimas, hasta que duela el tuétano de nuestros huesos. Hacer teología comienza

8. I. Ellacuría, "Discernir 'el signo' de los tiempos", en Escritos teológicos, vol. II, p. 134 (San Salvador: UCA Editores, 2000).

9. J. Baptist Metz, Por una mística de ojos abiertos, p. 93 (Barcelona: Herder, 2013). 
con un acto de atención que permite que la "desdicha de los otros entre en nuestra carne y nuestra alma"10.

El "ver" es el primer paso. Sin embargo, si se sigue el clásico "ver, juzgar y actuar" como método teológico, se puede caer en un malentendido fatal, al dar el segundo paso, "el juzgar". Este nunca se puede entender de la siguiente manera: primero se ve y luego se somete lo visto al juicio del teólogo. Más bien, el segundo paso consiste, en palabras de Ignacio Ellacuría, en "cargar con la realidad"

Cabe preguntarse por qué cuesta tanto y resulta tan difícil escuchar a las víctimas, dejarlas hablar, prestarles atención de verdad y no huir para dedicarse a asuntos que nos parecen académicamente de mayor importancia. Obviamente, cuesta soportar, aguantar y no evadir. Permitir que nos caiga encima el peso de la realidad que viven las víctimas exige un valor considerable, porque debemos actuar contraculturalmente. Debemos ir incluso en contra de aquello que parece conveniente para el trabajo académico. El esquema "ver-juzgar", "oír-interpretar", hay que transformarlo en "ver-asumir el peso", "escuchar-abrir espacio en nuestro corazón a eso que escuchamos".

Una teología que nace así no pretende ser vocera de las víctimas, "la voz de los sin voz", sino, más bien, dar la palabra a las víctimas. Nadie quiere oírlas. El gobierno no está interesado en lo que tienen que decir, porque eso pondría en evidencia la fachada de que todo va bien en el país. Muchas veces, las iglesias y otras instancias sociales tampoco desean escucharlas. Una exigencia elemental y el primer paso para frenar la violencia es crear espacios donde las víctimas sean escuchadas, donde puedan dejar de ser objeto de intereses cínicos para transformarse en hijos e hijas de Dios. Así, podrán comenzar su difícil camino hacia la sanación y la reconciliación. Si no hay salvación para las víctimas, no hay salvación para nadie.

Al triple paso de Ignacio Ellacuría, "hacerse cargo de la realidad, cargar con la realidad y encargarse de la realidad", Jon Sobrino suele añadir un cuarto paso: "dejarse cargar por la realidad". Esto significa que escuchar a las víctimas no es un acto altruista de los oyentes. Quienes se abren de verdad a las víctimas, reciben la vida a través de ellas. Paradójicamente, ahí donde la vida está amenazada, donde la muerte parece omnipresente, en ese mismo sitio, vibra la vida con una densidad sin parangón. La gracia parece irrumpir con preferencia en estos lugares de muerte. Ahí brota la "santidad primordial"12 de la que habla Sobrino. La bondad y la generosidad del corazón humano emergen con una inmediatez

10. Cfr. S. Weil, A la espera de Dios, p. 40 (Madrid: Editorial Trotta, 1993).

11. I. Ellacuría, "Hacia una fundamentación del método teológico latinoamericano", en Escritos teológicos, vol. I, p. 208 (San Salvador: UCA Editores, 2000).

12. Cfr. J. Sobrino, "La santidad primordial", Concilium 351 (2013), 45-57. 
y una pureza difícil de encontrar en otro lugar. Solo arrodillándonos ante este misterio de la vida, hay esperanza para nosotros.

Por esa razón, ahora queremos presentar las historias de María y Kevin. Es el grito, no desesperado, de dos de las víctimas actuales de la violencia, que azota con fuerza a El Salvador. Ellos, Kevin y María, luchan con todas sus fuerzas para vivir humanamente y con dignidad, en medio de la realidad de muerte que los rodea. Sus vidas y sus historias también son historias sagradas y de salvación.

\section{María y Kevin: dos historias de lucha y superación}

\subsection{María}

María es una mujer despierta y bajita en sus treinta años. Su rostro habla de las preocupaciones de una vida agitada y del trabajo arduo en el campo. Nació en una zona rural. De su niñez no cuenta mucho, solo que a los doce años se vino a San Salvador a trabajar. El trabajo siempre ha sido algo esencial en la vida de María y poder trabajar, en lo que sea, además de proveer económicamente para sus hijas, es para ella una alegría y le da dignidad.

"Me casé con el papá de mis hijas. [...] Vivíamos felices, porque teníamos casa y todo", relata María. Vivían en un barrio humilde del área metropolitana de San Salvador hasta que, a los pocos años, pasó lo que ella llama "el accidente". Entonces, todo cambió: "Él era motorista. [...] Le dieron siete balazos". El esposo de María sobrevivió como por un milagro. Pasó cuatro meses en coma y se recuperó poco a poco. El caso salió en las noticias. La nota de prensa decía que había reconocido a los pandilleros que le habían disparado. Un detalle fatal. La respuesta de las autoridades dejó frustrada a María: "Entonces, nos dijeron los policías que teníamos que desalojar la casa. Por eso, yo no creo en la justicia".

En vez de encontrar la protección de un Estado de derecho, fueron desplazados. Huyeron por primera vez. Se fueron a vivir a un cantón lejano de la ciudad, donde la familia del esposo, quien quedó inmovilizado durante varios meses por el atentado y no podía trabajar. Pasaron varios años en el cantón, junto con la suegra de María y otros familiares.

Fueron años de mucho sacrificio y de gran escasez para la familia. Hicieron su casa poco a poco, en un pedazo de terreno que les había cedido la suegra. "Recuerdo que para pagar el derecho del agua, [...] porque para poner el agua ahí vale 500 dólares el derecho [...], yo venía de vender y no comía, [...] pero me lo propuse, me quedaba hasta sin zapatos". La hija mayor estudiaba el bachillerato y María estaba embarazada de la pequeña.

Fue en ese tiempo cuando María empezó a notar un cambio en Yohana, su penúltima hija, que apenas tenía tres años y medio. "Yo le decía: ¿QQué tenés? ¿Qué tenés? ¿Qué te pasa? ¡Decime!'; y ella me decía: ‘Nada, te odio””. Así pasó el tiempo, pasaron los años y María sentía el rechazo de su hija. 
Un día, de la nada, desapareció Vanesa, su hija mayor, que estudiaba el bachillerato. "Pasé tres días que yo lloraba por mi hija y Dios me la devolvió. [...] Me la fueron a dejar por un lugar bien solo. Me le quitaron todito". A Vanesa la habían secuestrado. "Dice mi hija que los que la raptaron eran policías y le dijeron a ella: 'Solo porque nos han pagado, no te hacemos nada, no queremos verte en el cantón. Tienen que irse"'. María no entendía por qué le pasaba eso a su familia. Ella nunca se había metido con la gente, nunca había tenido problemas con nadie. Otra vez, María no dudó de las advertencias. Huyeron por segunda vez. Empezaron de nuevo, alquilando una casita en la ciudad. Trataron de llevar una vida con relativa normalidad.

Al cabo de unos meses, Vanesa confrontó a su mamá: "Mami, ¿qué hemos hecho? Volvamos al cantón. ¡No tengás miedo! Yo sé que Dios nos va a proteger". Volvieron a casa, de nuevo con la abuela, los tíos y los primos de las niñas. Fue entonces cuando Yohana le reveló algo a su madre. "Me dijo la niña: 'Mami, yo hoy sí te quiero decir una verdad que te va a doler, pero jurámelo que te vas a ir de aquí"." "Sí, hija, te lo juro que me voy a ir de aquí", le aseguró María, preocupada. Yohana dijo: "Mirá, mami, [...] cuando tú te ibas a vender, el sobrino de mi papi, [...] José, me violaba".

María no sabía qué decir. Habían transcurrido cinco años desde que había notado ese cambio en su hija. Ese rechazo profundo que no supo descifrar y que le dolía tanto. "¿Por qué no me habías dicho antes...?", fue lo primero que pudo preguntar. "Porque usted [...] no me iba a creer. Él me amenazaba [...] y me decía que si yo... si usted sabía, iba a mandar a matar a la Vanesa [...] y a usted. En ese río las iba a tirar", fue la respuesta de Yohana.

De una vez, entendió todo. Entendió que su hija, cuando ella salía al pueblo a vender pan, era violada por su propio primo. Yohana, en ese entonces, tenía tres años y medio y su primo dieciséis. María entendió el rechazo y el odio que su hija le había expresado durante tantos años. Entendió las circunstancias detrás del secuestro de Vanesa, su hija mayor. Entendió también que todo eso no podía haber ocurrido a espaldas de su suegra, la abuela de las niñas, a quien se las había confiado mientras iba a trabajar. De una vez, entendió todo, aunque le parecía inconcebible.

"Mire, yo sentí ganas de morirme, porque yo nunca pensé... esos niños [sus sobrinos] yo los bañaba, yo los aseaba de chiquitos y para mí, fue un golpe muy impactante", cuenta María. Ella sabía que su suegra no quería a las niñas. Se lo había echado en cara infinidad de veces. "¿Por qué, por qué no tuviste niños? Pobrecito mi hijo. Él, con esas niñas, va a ser la desgracia", solía reclamarle a María. Para la señora, las niñas no valían nada, eran una carga, una pérdida de tiempo. "Cuando mi hija empezó el bachillerato, me dijo a mí: '¿Y para qué le vas a dar bachillerato? Si esa, panzona te va a salir, como las mujeres de aquí que 
no sirven"”. Y agrega: "Yo no esperaba que me las quisiera, pero que, verdad, me las protegiera. Y ella vio lo que a la niña le pasaba".

Poco tiempo después, Yohana se empezó a sentir mal. María la llevó al médico y le detectaron un hongo vaginal. "Se me puso bien grave. Quizás cuando ya me dijo... ya desahogó". Aunque habían pasado seis años desde las violaciones, María no dudaba de que la infección tuviera que ver con la reciente revelación de su hija. Como que en su cuerpo algo hubiera despertado. La doctora, al escuchar lo que había ocurrido, se escandalizó: "Me dijo: 'No, tú tienes que denunciar. [...] Si tú no denunciás, sos cómplice"".

Nada hubiera querido María más que denunciar ante las autoridades ese hecho atroz. Nada hubiera querido más que ver tras las rejas al que había violado a su hija de tres años y medio. Pero a la vez, sabía que eso sería fatal. "El día que usted toque a uno de mis niños, usted se va a arrepentir", le había advertido su suegra, en más de una ocasión. Estas advertencias no carecían de fundamento. Uno de los nietos de la señora y una parte de su familia eran pandilleros, y María sabía muy bien qué significaba eso.

Un día, viernes en la tarde, capturaron a quien había violado a su hija. María no lo había denunciado. La doctora, en su afán por hacer justicia, había informado a la fiscalía sobre el caso. Lo que, en sí, fue un acto de buena voluntad, marcó un antes y un después, en la vida de María y su familia. Si no lo había sido antes ya, ahora sí empezaba para ellos un verdadero infierno.

Huyeron por tercera vez. Huyeron sin nada. Sin dinero, sin equipaje, sin rumbo. Buscaron refugio en casa de familiares, de amigos, de conocidos, de desconocidos.

Dormimos un mes en un cuartito, en el suelo, sin colcha, sin nada. Mis niñas pasaron quince días sin cambiarse de ropa. Y nos buscaron ahí. Llegó mi suegra a buscarnos a ese lugar. Ella sabía dónde yo podía estar. Llegó a la casa de mi mamá.

Hasta la fecha, llevan siete meses vagando, caminando errantes de lugar en lugar. Cinco veces se creían seguros, cinco veces tuvieron que salir huyendo. Esto ha dejado huellas profundas en todos ellos. Las niñas hacen preguntas. "Mami, ¿por qué nos movemos tanto? ¿Por qué no podemos llegar a casa?". "A cada lugar que vamos, dejamos un corazón". Al poco tiempo, las niñas se enfermaron. María las llevó a pasar consulta médica, les hicieron todos los exámenes, pero no encontraron nada.

Pasaron tres meses que yo no tenía vida. Era de noche y mis hijas gritaban. Es bien duro saber que hay gente que hasta debajo de las piedras lo busca a uno. Y parece mentira [que] dice la gente: “HHay paz!”. No, para mí no hay paz. 
Del último escondite, huyeron una madrugada. Era un cantón rural donde había que caminar una hora para salir y llegar a la carretera. Un hermano de María vivía ahí. El lugar, a lo largo del tiempo, había caído por completo en manos de una de las pandillas. Cuando llegaron por primera vez, al esposo de María lo desnudaron. "Nos preguntaron que si huíamos de algo, y yo les dije que no. 'Cómo no', dijeron, 'ustedes vienen huyendo de algo'". Mientras estaban viviendo ahí, María se moría de miedo por sus hijas. No las dejaba salir, no podía. "Si el jefe quiere esa niña, tiene que obtenerla y yo sentía pánico". En esa madrugada, salieron, después de enterarse de que los pandilleros habían girado órdenes de buscarlos nuevamente. Para María, es un milagro que los pandilleros no los descubrieran. "Gracias a Dios, pude salir. Y eso me da alegría, que pude salir ahora y estoy lejos otra vez. No sé por cuánto tiempo".

María está viva. Está con su esposo y con sus hijas. Y María tiene sueños.

Yo quisiera tener mi vida diferente, la que tenía antes, trabajar, sudar para ganarme el pan de cada día. [Quisiera] ser libre [...], tener paz y no pensar "Dios, aquí no puedo salir, porque no puedo. Me siento presa". [...] Quisiera estar lejos y poder hacer, poder trabajar, poder sentirme segura, llegar a un lugar donde yo diga: Aquí estoy. Voy a ver qué hago de comer. ¿Qué quieren de comer?

\subsection{Kevin}

Digamos que desde el más pequeño hasta el más grande, tenía que pelear: [...] en la escuela, en la casa, en la comunidad, aun hasta con la propia familia, uno tenía que, en cierto momento, ser violento para defender lo que uno pensaba.

Kevin es hijo de la calle. Allí aprendió a robar, a mentir y a hacer daño a las personas. Nadie lo empujó o lo incitó. No entró en ese mundo por culpa del azar o la casualidad. "La calle la conocí desde que mi mamá se fue para los Estados Unidos. Desde los siete años hasta los doce". Ella entró en Estados Unidos ilegalmente para, desde allí, ayudar a la economía familiar. Fue un tiempo duro para Kevin y sus hermanos. La ausencia de su madre creó un gran vacío en sus vidas. Por otra parte, ella era la que controlaba sus amistades y sus salidas: "Ella ya sabía de lo que nos estaba protegiendo".

Kevin es el tercero de cuatro hermanos. Cuando era niño, su hermano mayor, Diego, se vinculó con las pandillas como "civil activo". No era miembro de ninguna pandilla, pero hacía pequeños encargos, movía drogas y armas. "Otras veces, por lo que él me había contado, que habían ido a ciertas comunidades en que se habían agarrado a disparos con los chicos contrarios".

Kevin, poco a poco, fue entrando en el ambiente del que su hermano mayor se estaba retirando. Por eso, Diego trató de protegerlo. 
Cuando empezó a ver eso, que yo también seguía los mismos pasos que él, me aconsejaba o, muchas veces, él me delataba con mi papá. Y yo me enojaba y decía: "¡Puta!, este maje anda haciendo las ondas y quién es él para decirme que yo no". Pero él estaba ya consciente, a una edad que él ya se había retirado de todo eso.

Diego no fue la única voz que intentó apartar a Kevin de aquel ambiente de violencia que lo rodeaba.

Conocí mucha gente que, como dirían, es la gente menos indicada como para darme un buen consejo, si son asesinos, ladrones, estafadores y mafiosos, en pocas palabras. Me aconsejaban y me decían: "Kevin, esto no es vida, si vos estudiando deberías estar, allá en tu casa deberías estar".

Kevin estudiaba, iba a una escuela pública cercana a su casa. Era un lugar de división y frontera entre la MS y la Mara 18. En aquel contexto de violencia y enfrentamiento, Kevin solo aprendía a esconderse de la policía.

Me acuerdo que iba a cuarto grado y nosotros, a veces, entrábamos con armas a la escuela. Una vez, pasó que a un compañero se le cayó la pistola y se salieron unas balas por los pasillos. Bueno, entre los pupitres. De la nada, una compañera levantó una bala y le dijo al profesor. El profesor llegó y nos comenzó a explicar que si esa bala le pegaba en la parte de abajo, se iba a disparar y podría herir a alguien del aula. Escondimos la pistola. Yo me subí a la segunda planta del edificio y la envolví con unas camisas y la dejamos. Ya después, entraba la policía, hacía requisas para ver si encontraban armas, drogas o cualquier tipo de cosas.

Cuando Kevin tenía doce años, su madre regresó de Estados Unidos. Pero ya todo había cambiado. Las relaciones en su casa se fueron enrareciendo hasta el punto que Kevin, con tal solo doce años, echó a su padre de la casa por golpear a su mamá.

Al quedarse sola, la madre intensificó el control sobre sus hijos. Ya no vigilaba únicamente las horas de entrada y salida, sino que incluso les impidió que fueran a visitar a su padre. Kevin no soportó tanta presión: "Llegó un momento en el que le dije: 'Mire, yo me voy de la casa, ya no aguanto'. Y en serio me fui". Estaba a punto de cumplir los catorce años.

Kevin se puso en contacto con un amigo y entre los dos alquilaron un cuarto, en una población algo alejada de su casa. Aun así, Kevin no dejó de ir a la escuela. Pero para hacer frente a los gastos del alquiler, de la comida y del transporte para ir a la escuela, Kevin y su amigo comenzaron a robar. Y lo que comenzó con robos simples, acabó en tráfico de marihuana y cocaína. "A la semana, estaba sacando, de vez en cuando, 150 o 200 dólares a la semana. Después, sacaba de 300 a 400 dólares. Así, poco a poco". El negocio con las drogas fue creciendo y tuvieron que ampliar la plantilla. Llamaron a su primo. Kevin tenía catorce años. 
Una vez, hubo un enfrentamiento [con la policía], en el cual a un amigo le estaban disparando y por salir a ver, una bala le pasó levantando toda la carne. Tuvo tanta suerte que no le pegó más abajo, solo fue el rozón.

Después de ese enfrentamiento con la policía, decidieron desintegrar el grupo y alejarse de ese mundo. Quizá el miedo fue una de las razones para abandonar el comercio de las drogas. "Hubieron [sic] veces que íbamos a lugares a traerla y mirábamos unas personas, como dicen, armados hasta los dientes. Tatuados". Pero la motivación principal fue otra.

Veíamos que con la marihuana no había problema, pero ya con la cocaína era un punto más crítico, porque ya no solo eran comerciantes, sino también algunas instituciones del gobierno y personas de gran peso aquí, en El Salvador, como empresarios, que también están fuertemente vinculados al tráfico. [...] Vimos que no era un juego tan sencillo, de vida o muerte.

Alejado del mundo de las drogas, Kevin se juntó con otro primo y retomaron el camino de los robos.

Empezamos a robar, y en una de esas, secuestramos un bus de la ruta 79. Secuestramos todo el bus y le quitamos todas las pertenencias a la gente, igual dinero. En lo que nos íbamos a bajar, un tipo se levantó. No sé si era policía, pero el tipo andaba armado y nos empezó a disparar adentro del bus. El bus aún iba andando y nos tiramos. Al último chero ${ }^{13}$ que iba con nosotros, alguien lo agarró de la camisa y se la rompió, pero también logró escaparse. Él agarró por otro rumbo y nosotros otro rumbo, porque el tipo que se había levantado y nos disparó, todavía se bajó del bus y nos salió persiguiendo disparándonos.

Kevin y su primo se escondieron donde pudieron, pero, al final, la policía los encontró y los llevó a las bartolinas ${ }^{14}$. Allí estuvieron encerrados durante dos semanas. Finalmente, quedaron libres por ser menores de edad.

$\mathrm{Al}$ salir de las bartolinas, todavía con quince años, Kevin se enteró de que iban a operar a su padre y fue a visitarlo a su casa. "Lo vi bastante grave y yo le dije: 'Me voy a ir con usted para estarlo cuidando'. Así que ese tiempo estuve con él. Yo le hacía las cosas". El tiempo que pasaron juntos hizo que su relación se fuera fortaleciendo. "Yo estuve con él. Poco a poco, nos fuimos entendiendo". Kevin acabó yendo a vivir con su padre.

Por esos días, Kevin se juntó con unos amigos que conocía desde pequeño, "otros cheros que también fumaban". Con ellos empezó a conocer lo que él

13. Chero: amigo.

14. Bartolina: calabozo, aposento de cárcel. 
llama "la cultura de Sívar15". "Los punk, rasta, skinhead, chicos que bailan break, baggy. El skate fue el que más me gustó". Entonces, sucedió algo que cambió su vida. "Me acuerdo que agarré una tabla y sentí esa sensación. Me gustó bastante e hice lo imposible por conseguir una tabla". Kevin sintió algo que hasta entonces no había percibido. "Después, en vez de ir a hacer cosas, prefería patinar con otros amigos". En medio del humo de los cigarros y los porros, entre adolescentes y jóvenes tatuados, Kevin encontró una nueva forma de vida. Así, desde los quince años, Kevin ha pasado alejado del robo y la delincuencia. Ahora tiene veinte años.

Han sido cinco años en los cuales he tenido un proceso personal bastante loco, porque he cambiado bastantes cosas de las cuales antes nunca me imaginé que iba a cambiar. Igual, hay mucha gente que desde la infancia me conoció y me ven ahora y me dicen: “'Cómo has cambiado!”, y yo me pongo a reír.

Kevin ha abierto nuevos espacios vitales, lo invitan a procesos y se va formando. Un amigo asesinado fue quien más influyó en su cambio. Él animó a Kevin a formar parte de un comité para luchar por los derechos de los jóvenes. "Fui a la reunión. De repente, vi a unos chicos de mi misma edad y empiezan a hablar de política. Y yo me quedé: 'Es otra loquera aquí'. Me gustó". Ahora, Kevin tiene otros sueños, nuevas metas.

Es un sueño compartido con otro amigo, con el que falleció, porque me acuerdo que él me comentaba que siempre quería hacer algo en donde los jóvenes se vieran unidos, en pocas palabras. Crear un espacio o una casa en donde los jóvenes puedan venir y alejarse de los problemas.

El hecho de haber cambiado de actitud y el compromiso con los jóvenes y la lucha por sus derechos no le ha evitado problemas. Al contrario, ahora que trabaja por lo que es justo y se mantiene dentro de la ley, es cuando tiene más enfrentamientos con las fuerzas del Estado. "Hoy, prácticamente, son el ejército y la policía los mayores violentadores de los derechos humanos". De ellos ha recibido insultos, golpes y disparos.

Ya bastantes veces me han detenido. Por cierto, la última vez fue un proceso antipandillas, me detuvieron y solo por el hecho de vivir en una zona roja; una zona peligrosa. Y más por el hecho de ser joven y estar tatuado, la policía te ve como una amenaza.

En una ocasión, Kevin caminaba por la calle con unos amigos. Salían de una fiesta de graduación. Era ya noche, alrededor de las once. Iban hablando, cuando pasó a su lado una patrulla de la policía.

Sin preguntar media cosa, empiezan a disparar a los primeros desde adentro del carro. Yo iba con otro amigo y él me jaló hacia un poste y había una

15. Sívar: forma popular y juvenil de referirse a San Salvador. 
colchoneta, una cama. Me agaché y empecé a ver quiénes eran [...] vi que era una patrulla y veo que los policías se iban bajando de la patrulla, y yo dije: "Si me agarran acá, es para que me den verga, me suban a la patrulla, me desaparezcan o que me lleven a otro territorio contrario y me dejen aventado"16. [...] En eso, cuando salí a ver, vi que el policía ya venía subiendo las gradas y en ese momento mi reacción fue huir del lugar. Nomás salgo del poste y de la colchoneta, vi los primeros destellos del fusil. Salí corriendo y el policía venía detrás de mí disparándome. Creo que fueron entre quince a dieciséis disparos que me dejó ir el policía. Hasta sentí las ráfagas. En eso, que sentí la ráfaga, vine y me tiré hacia otro muro para protegerme y solo escuché cómo las balas pegaban en la pared, [...] entonces, me tiré ${ }^{17}$ un muro como de cuatro o cinco metros, me tiré otras quince gradas de un salto y subí a mi edificio y ya estaba en mi casa. Mi hermana estaba en la computadora. Todavía me dice: "¿Escuchaste los disparos?". Y me ve la cara y me dice: “QQué te pasa?". Y yo le dije que a mí era que me venían tirando. Le cambió la expresión, se asustó.

Kevin ha aprendido que la violencia nunca es una solución. A pesar de su pasado violento y de los ataques que actualmente sufre por parte de la policía, está convencido de que la lucha ha de hacerse por vías pacíficas. Asegura que nunca volvería a los tiempos de robos y drogas. "¿Si quiero volver a ese pasado? Rotundamente, cien por ciento, no. [...] He aprendido, a través de otras formas, a gestionar mis propias cosas".

\section{El escándanlo de la violencia y el daño que causa en las víctimas}

Los relatos de Kevin y María -y los de las otras trece personas- hablan por sí mismos. El solo hecho de prestar atención a sus vidas y sus palabras es ya en sí un acto teológico, porque nos descubre al Dios presente entre los últimos. Las siguientes reflexiones nacen de ese estar atentos a las víctimas y sus voces, que gritan con fuerza, pero que tantas veces son acalladas y marginadas. En ellas, toma cuerpo el escándalo de la violencia que sufren cotidianamente.

Los niveles y las expresiones de la violencia actual son escandalosos y, en palabras de Ellacuría, hacen necesaria "una lectura teológica de esta misma situación que para la fe no corresponde a los designios de Dios"18. En esta realidad, el solo hecho de visibilizar el horror y de señalar las injusticias tan evidentes constituye ya una "denuncia desenmascaradora" 19 , exigida por el

16. Aventado: tirado, arrojado, abandonado.

17. Me tiré: salté.

18. I. Ellacuría, "Hacia una fundamentación del método teológico latinoamericano", op. cit., p. 197.

19. Ibidem. 
mismo Ellacuría, que cuestiona las políticas públicas y las formas de convivencia en el país.

Ahora bien, esta denuncia desenmascaradora debe ser responsable y contundente. En todo momento debe estar comprometida con la verdad de los hechos y buscar la justifica y la dignificación de las víctimas. Sobrino dice lo mismo, cuando habla de la "honradez con lo real [que] super[a] mentira y encubrimiento con la voluntad de verdad, [pone] nombre a los millones de víctimas y mártires [y hace] memoria de ellos, de cuya savia vivimos" ${ }^{20}$.

\subsection{Asesinados y desaparecidos}

El homicidio es la forma más objetiva, más evidente y más cruda de la violencia. Quitarle la vida a alguien es un acto definitivo, irreversible. Lo que queda es el cadáver, el cuerpo muerto y vejado de la víctima. La muerte, en general, pero la muerte violenta y repentina, en particular, deja un vacío en las familias y entre los amigos que difícilmente se vuelve a llenar. Puede, incluso, desmoronar estructuras familiares y sociales enteras y dejarlas a la deriva.

Aunque no hayan perdido a ningún familiar por asesinato, prácticamente todos los salvadoreños han sido testigos de homicidios o de escenas de crimen. Una consecuencia de esta realidad es cierta normalización de la violencia en la sociedad. La muerte violenta ha dejado de ser un escándalo. Las víctimas de los veinticuatro homicidios diarios parecen no tener nombre, ni rostro, ni historia. Algunas llegan a tener unos segundos de fama en los noticieros. Los cuerpos abatidos en su sangre y los familiares quebrados en llanto logran saciar momentáneamente el morbo de los periodistas y los televidentes, antes de pasar al corte comercial y volver a la rutina diaria. Las víctimas de todos los días son expresión del "iqué mal estamos!" y pasan al olvido colectivo.

En El Salvador, veinticinco años después de la firma de los Acuerdos de Paz, no solo sigue habiendo asesinatos, sino que, frecuentemente, estos se cometen con saña y barbarie. Juan, un joven padre de familia, que debió huir ante las amenazas concretas de una de las pandillas, recuerda el terror que se vivía en su comunidad.

Uno, cuando ve o recuerda a jóvenes... cómo los despedazaban, cómo los asesinaban, con arriba de unos quince, veinte balazos, [...] otros, degollados, muchas puñaladas. [...] Hay otros, de que para sacarles la información, lo que les hacían era empezarles a volar los dedos, las partes, todo. Hicieron muchos tipos de asesinatos, torturas.

20. J. Sobrino, Fuera de los pobres no hay salvación, p. 40 (San Salvador: UCA Editores, 2009). 
En El Salvador, familias enteras sufren hoy otra forma de tortura psicológica más sutil: la de los muertos que no dejan rastro. La desaparición forzosa, práctica habitual durante la guerra civil, sigue perforando el tejido social en la actualidad. Ciertamente, muchos familiares, a medida que pasan los días sin noticias de sus seres queridos desaparecidos, van perdiendo la esperanza de encontrarlos con vida. Sin embargo, la ausencia de un cadáver no les permite asumir la muerte.

La desaparición forzosa de un ser querido introduce en la tortura de la incertidumbre, un dolor cruel y profundo, que solo puede ser remediado con la verdad $\mathrm{y}$, en último término, con la aparición del cuerpo, ya sea con vida o muerto. "Quisiera algún día encontrar a mis hermanos y tener dónde irlos a llorar con mis sobrinas". Así expresa Valeria su anhelo más hondo, ante la desaparición de sus dos hermanos. Aída, cuyo sobrino fue desaparecido hace varios meses, comparte ese dolor, entre lágrimas.

Ha sido muy doloroso, definitivamente. [...] Es bien difícil levantarse todos los días y ver que las hojas caen de los árboles, y pensás: y ¿adónde está?, o estás comiendo y... pensás si está comiendo o si lo mataron... es tan difícil. [...] Ya no sabemos ni qué pensar, si decir que está muerto o está vivo. Pero la incertidumbre ahí está, el dolor ahí está.

\subsection{La normalidad de ser violada}

Una de las violencias menos reconocidas y a la vez más latentes es la violencia de género, que abarca desde el acoso callejero, la discriminación y el abuso sexual hasta delitos tan graves, pero muy comunes, como la violación sexual o el feminicidio.

"El día de mis quince años, él me violó". El testimonio de Aída es duro, pero no es ninguna excepción en El Salvador. Es reflejo de una cultura de la violencia contra las mujeres y de una praxis patriarcal perversa y muy extendida. Todas las mujeres, y varios de los hombres entrevistados en el contexto de esta investigación, relatan experiencias de violencia de género sufridas o presenciadas en su núcleo familiar inmediato. En varios casos, la agresión proviene de la figura paterna, por ejemplo, del padrastro o de otros familiares, como los tíos o los primos, quienes conviven con las víctimas en el mismo hogar y se aprovechan de su condición física, moral y social superior.

Esto lleva, en algunos casos, a un mayor escándalo o decepción, mientras que, en otras ocasiones, puede resultar en encubrimiento e incluso en complicidad. María, por ejemplo, en el primer relato presentado antes, reacciona con indignación al enterarse de que su hija de tres años de edad había sido violada por su propio sobrino de dieciséis años: "Yo sentí ganas de morirme, porque yo nunca pensé... Esos niños yo los bañaba, yo los aseaba de chiquitos y para mí, fue un golpe muy impactante". 
Aída, por el contrario, encuentra incomprensión y rechazo en su madre cuando, siendo aún una niña, le confesó haber sido abusada sexualmente por su padrastro: "Ser víctima de abuso sexual por parte de un padrastro no es fácil, que tu mamá esté viendo y te diga que no es cierto...". Años después, su propia madre, por intereses socio-económicos, aprobó y promovió la violación y luego el matrimonio forzado de Aída con un hombre mucho mayor que ella. "Prácticamente, fui obligada a estar con esta persona, por un bienestar económico, a mis quince años. [...] Mi mamá quería que yo estuviera con él, para que nos sacara, dizque ${ }^{21}$, de la pobreza".

Este último ejemplo, junto con otros, sugiere que la violencia de género va más allá de la relación violenta hombre-mujer. El machismo es un problema social muy profundo que, paradójicamente, en muchas ocasiones, es reproducido por las mismas mujeres, quienes, por falta de patrones alternativos, asumen esta injusticia como la normalidad. Esto se refleja en la relación que María tuvo durante muchos años con su suegra, de cuyas amenazas ahora está huyendo. "A las niñas me les decía: 'Ustedes no sirven para nada'. Cuando mi hija empezó el bachillerato, me dijo a mí: "¿Y para qué le vas a dar bachillerato? Si esa, panzona te va a salir, como las mujeres de aquí que no sirven"".

El desprecio generalizado hacia el género femenino, incrustado en una masculinidad fallida, clama al cielo y socava los fundamentos de la sociedad a largo plazo.

\subsection{Una generación crece en el encierro}

Los jóvenes entrevistados, residentes en barrios urbanos marginados, son los que más ponen de relieve la normalización de la violencia en sus vidas. El miedo constante de ser víctima de las pandillas o de la represión estatal ha llevado a muchos a buscar la manera de adaptarse a esta situación límite. Así, pasan gran parte de su juventud en condiciones de encierro, en sus viviendas o colonias. Roberto, estudiante de bachillerato de diecisiete años, vive en una zona muy conflictiva, donde pandillas, policías y un grupo de sicarios han librado una guerra. "Nosotros sentíamos que [...] en algún momento podíamos salir en mal tiempo de la casa y terminar en un fuego cruzado ahí y tal vez salir lesionados".

Aunque los jóvenes son particularmente afectados por la violencia, es la población en general, incluidos los adultos, los ancianos y los niños, la que sufre el miedo constante. No sorprende entonces que los adultos, angustiados por la vida de sus hijos, sobrinos o nietos, hagan todo lo que está a su alcance para protegerlos.

21. Dizque: al parecer, presuntamente. 
María, con sus cuatro hijas, sabe que ese miedo no es una exageración. Según su relato, citado antes, hace pocos años, una de sus hijas fue secuestrada por un grupo de policías y estuvo desaparecida durante varios días. "Mi hija grande, tengo una de catorce años, no la podía sacar ni tan siquiera afuera, [por] la edad que ella tiene... Si el jefe [de la pandilla] quiere esa niña, tiene que obtenerla y yo sentía pánico".

Hoy, en El Salvador, vive y crece una generación entera bajo el régimen de toque de queda permanente. El confinamiento y desconfianza no se limita solo a los sectores más pobres y marginados de la población. El fenómeno es generalizado, comprende a la sociedad en su conjunto, aunque adquiere modalidades diversas. Las zonas residenciales y las colonias de la clase media y alta cada vez se aíslan más. Las calles y los pasajes urbanos con portones cerrados aumentan constantemente. El papa Francisco se refiere a esta realidad, cuando habla de "muros que encierran a unos y destierran a otros. Ciudadanos amurallados, aterrorizados, de un lado; excluidos, desterrados, más aterrorizados todavía, del otro". Y nos cuestiona con la siguiente pregunta: "¿Es esa la vida que nuestro Padre Dios quiere para sus hijos?"22.

Ante la realidad oprimente, la indiferencia y la apatía constituyen un escándalo, que no sabe más que estigmatizar. Prevalece el desconocimiento de la voz que pregunta a Caín, después de haber asesinado a su hermano: "¿Dónde está Abel, tu hermano?" (Gn 4,9). La respuesta a esa pregunta hecha por nadie es el silencio. Pareciera que en la sociedad salvadoreña, por desgracia o privilegio, nadie es guardián de su hermano. Esto es grave. La desconfianza, el aislamiento o la indiferencia ante el sufrimiento del prójimo hacen a todos corresponsables de su muerte.

\subsection{La violencia de la injusticia}

Una de las violencias que pasa más desapercibida, pero que es la que produce más víctimas, es la injusticia social o la violencia estructural, a la cual Ignacio Ellacuría llama la "violencia originaria, raíz y principio de todas las demás violencias sociales" $"$.

Para las víctimas entrevistadas, la expresión más evidente y cruel de la injusticia social es la impunidad. El dolor de no ser escuchados y no ser reconocidos como víctimas resuena en todos los relatos de los entrevistados.

22. Papa Francisco, "Discurso del Santo Padre Francisco a los participantes en el Encuentro Mundial de Movimientos Populares", 5 de noviembre de 2016. Disponible en http:// w2.vatican.va/content/francesco/es/speeches/2016/november/documents/papa-francesco_20161105_movimenti-popolari.html.

23. I. Ellacuría, "Trabajo no violento por la paz y violencia liberadora", Concilium 215 (1988), 86. 
Verónica, víctima de desplazamiento forzoso, después del asesinato de su hijo mayor, ha vivido en carne propia la impunidad y el abandono de las autoridades, que experimenta como otro acto más de violencia.

No poder llegar ante la policía y decirles: "Mire, me pasa esto y esto", y que ellos me digan: "Vamos a hacer tal cosa", en beneficio de uno. [...] No hay ese beneficio. Entonces, para mí, ese es un hecho de violencia. [...] Desde que lo mataron, a mí me avisaron que lo fuera a recoger a Medicina Legal. Eso fue todo. Pero de ahí, la policía, ni nunca nadie llegó adonde mí a decirme: "Mire, señora...", nadie, nadie. Hasta la fecha, esa muerte de mi hijo así está.

La impunidad es una violencia pasiva, pero igualmente lesiva, que pone en evidencia que la sociedad y el Estado no han logrado construir soluciones eficaces para las complejas e inaplazables necesidades de las víctimas.

Pero el escándalo de la impunidad es insuficiente. El Estado reprime y violenta a las víctimas para acallar sus voces disidentes y restablecer así un presunto orden. De nuevo, los hombres jóvenes de los barrios marginados y de los cantones pobres del país le sirven como chivo expiatorio para demostrar supuestos avances en la seguridad ciudadana. Volvieron las torturas, las detenciones arbitrarias, las desapariciones y las ejecuciones extrajudiciales. Los rostros no importan, solo los números. En tiempos de miedo, los derechos humanos sufren de inflación.

Kevin, el joven artista urbano y activista político, cuyo relato incluimos en este artículo, ha sido agredido por policías y soldados, en diversas ocasiones, como dice él, simplemente por "vivir en una zona roja, una zona peligrosa y más por el hecho de ser joven y estar tatuado". Kevin asegura que no puede denunciar esos hechos, porque quedaría expuesto a la venganza de los compañeros. "Eso sí ya me ha pasado con militares y policías [...] Me han amenazado: 'Te veo malabareando, te voy a matar', me han dicho".

Todos los entrevistados, sin excepción, se sienten abandonados por el Estado, en su búsqueda de justicia, y varios, además, han sufrido el acoso y el abuso del poder público. María reúne en su reclamo las voces de todas las víctimas. Casi de manera profética, eleva su plegaria al cielo con la certeza de que otro mundo es posible y necesario.

Yo cómo deseara que los que están más alto que nosotros, los que tienen el poder, se preocuparan un momento, se detuvieran a pensar y decir que la gente más marginada son la gente que vive ahí en los cantones... Y si se pusieran a analizar y no pelearan cada vez que hay votación, pelear por el voto, sino que por ver las necesidades. 


\section{Vida en medio de la muerte}

La Escritura y la experiencia del pueblo de Israel y el evangelio afirman como verdad incuestionable que Dios toma partido por los pobres y los excluidos de la historia. "Bienaventurados los pobres, porque de ellos es el reino de Dios" (Lc $6,20)$. Dios ama con predilección a los pobres que sufren. $\mathrm{O}$, mejor dicho, porque sufren, Dios los ama. En medio del desconsuelo, de la angustia y de la muerte, se revela el Dios que es amor y compasión para los pobres y marginados.

Estas afirmaciones pueden parecer vacías o alejadas de la realidad, incluso crueles y ofensivas, a quienes, día a día, viven la pobreza y el abandono. Sin embargo, las víctimas a las que hemos entrevistado son las que nos han hablado de vida y esperanza, en medio del sinsentido y la crueldad. Son ellas las que encuentran espacio para el optimismo y la lucha, donde la división y los caminos sin salida son una realidad. Son ellas las que reconocen el amor de Dios, expresado de múltiples modos y maneras, cuando lo normal sería negar su existencia o culparlo por permitir, pasiva o malévolamente, tanta barbarie.

Hasta ahora, en los apartados anteriores, hemos presentado una realidad de violencia y de cruz; una realidad escandalosa de muerte y de pecado. Vamos a ofrecer ahora la vida y la esperanza, que surgen en medio de esa realidad de violencia y muerte. Cuando una víctima abre caminos de reconciliación y de paz, se convierte en signo profundo de esperanza, de vida y de opción por ella. Las víctimas, más allá de experimentar el horror de la crueldad social y personal, nos rescatan y nos salvan. En cierto modo, sus vidas y la historia que aflora en ellas, como dice Sobrino, "nos puede remitir a lo más originario nuestro. Y nos puede remitir a Dios"24.

\subsection{Voces autorizadas}

Cuando las víctimas hablan, la única respuesta posible es la escucha atenta y silenciosa. Las palabras sobran. Muchos han pasado por esa experiencia. Encontrarse con alguien que comparte su dolor por alguna tragedia, encoge el corazón y multiplica la cercanía y el cariño hacia esa persona que sufre. En ese momento, la palabra se convierte en consuelo inútil.

Las víctimas hablan con la autoridad que les da el sufrimiento en carne propia. Ellas viven la agonía que nadie quiere para sí, ni para los demás. Por eso, los pobres y los sufrientes, cuando comparten sus vidas, se convierten en voz autorizada. Desde su sufrimiento, dan razones para la vida y la esperanza. Las víctimas, ellas y ellos, son portadores y voceros de la vida. En cierto modo, de Dios. "En el gemido de la creación y de la humanidad, hemos de discernir la presencia clamorosa del Espíritu, que busca salvación, liberación, justicia,

24. J. Sobrino, "La santidad primordial", op. cit., p. 47. 
plenitud escatológica, precisamente desde donde hay más dolor y aflicción"25. Las víctimas se convierten en palabra autorizada para hablar del Dios que es vida. Pero también son grito autorizado que despierta del letargo y abre los ojos a la realidad que atropella con su injusticia.

\subsection{Voces que despiertan del letargo}

Las víctimas entrevistadas no han hablado desde teorías o razonamientos muy meditados y estructurados. Con sencillez, nos han compartido sus vidas y sus sufrimientos. $\mathrm{Y}$ al hacerlo, han ofrecido vida.

En primer lugar, ellas hacen que despertemos de la indiferencia y la pasividad. Verónica, una mujer de 49 años, que, junto a su esposo Alfredo, ha vivido en permanente desplazamiento por la violencia de las pandillas, confiesa: "Somos del mismo país, todos somos pobres. Y yo no sé cómo uno le va a pedir al otro, que sabe que no tiene". Sus palabras recuerdan las de Mons. Romero, en su última homilía: "Hermanos, son de nuestro mismo pueblo. Matan a sus mismos hermanos campesinos" 26 . Todos son pobres, todos son sufrientes. Se trata del pueblo golpeando al pueblo.

Ante esta realidad cruel, las víctimas claman contra la pasividad. Ese es el lamento de Aída: "No dicen nada, no denuncian nada, no hacen nada, se quedan callados por el mismo temor a represalias". Este es el grito de una mujer que sigue luchando para conocer la verdad sobre la desaparición de su sobrino, posiblemente a manos de la policía. Es un grito que contrasta con la quietud generalizada ante tanta barbarie. Las víctimas nos hacen un llamado a salir de la zona de confort para hacer frente a los problemas y así dejar el abandono y la pasividad.

\subsection{Vidas que no se dejan atropellar por la historia}

Muchas víctimas no se dejan arrastrar por el sufrimiento en el que viven sumergidas. Algunas se levantan, se ponen en pie y continúan avanzando para esperanza de muchos. Empujan así el carro de la historia, en lugar de dejarse atropellar por él, tal como lo expresa Ellacuría en su artículo sobre el pueblo crucificado. Indudablemente, este es otro elemento generador de vida. Uno de los grandes males de esta sociedad es la violencia de las pandillas, la cual forma parte del ambiente letal de violencia desmesurada que invade al país. Aun cuando muchas de las víctimas entrevistadas reconocen el entorno violento en el que viven, se resisten a ser parte de él. No se dejan arrastrar por la corriente violenta.

25. V. Codina, El Espíritu del Señor actúa desde abajo, p. 57 (Santander: Sal Terrae, 2015).

26. Óscar A. Romero, Homilías, t. VI, p. 453 (San Salvador: UCA Editores, 2009). 
Aída relata la respuesta de su sobrino ante el acoso de los pandilleros: "Ellos insistían mucho para que él se metiera a la pandilla y él dijo que no... él dijo que no. Entonces, como que ahí empezó todo". El sobrino de Aída es un claro ejemplo de la resistencia a la violencia. A sabiendas de lo que pudiera suceder, él no entró a la pandilla, pero lleva más de un año desaparecido.

Christian, un joven de dieciocho años, que vive en una colonia muy peligrosa y que ha sido golpeado tanto por jóvenes afines a las pandillas como por la policía, afirma que le ofrecieron entrar a formar parte de aquellas. "Yo pensaba diferente. 'No'mbre', decía yo. Así como se ven las noticias de tanto muerto por andar en esto y aquello... [...] no me conviene porque muerte lleva a la muerte, $o$ sea... a nada bueno". Su opción es seria y, ciertamente, arriesgada. Es una opción personal por la dignidad y la humanidad. Christian se negó a entrar en el mundo violento de las pandillas, aun cuando otros, sus amigos, habían sido asesinados por resistirse, al igual que él. Sin embargo, Christian dice: "No me conviene, porque muerte lleva a muerte".

\subsection{Vidas en medio de un mar de muerte}

Es triunfo de Dios que, en medio de las fuerzas que dan muerte, hay quienes recuperan la esperanza y se constituyen en islas donde la vida se hace posible. En la historia de cada persona, también hay islas de vida.

Kevin, el joven de veinte años, cuyo relato hemos reproducido antes, vivió, según sus palabras, en el mundo de la calle, donde aprendió sus modos. Cuando era niño, entraba armado en el colegio. A los doce años, echó a su padre de la casa y a los catorce años, comerciaba droga y asaltaba autobuses. Sin embargo, en medio de esa historia de muerte, también hay signos de vida. Sus padres, conocedores del contexto violento que lo rodeaba, fueron capaces de ofrecerle pequeños momentos de vida y humanidad. "[Mi padre] me ha ayudado bastante. Ya que también, como sea, siempre me ha regalado un libro [...] y me gustó. Igual, mi mamá me regalaba libros siempre, sabían que me gustaba leer". Según su propio relato, un amigo suyo, cuando tenía diecisiete años, lo ayudó a salir del mundo de la violencia con el solo hecho de prestarle una tabla para hacer skate, para patinar. "Me acuerdo que agarré una tabla y sentí esa sensación, me gustó bastante e hice lo imposible y conseguí una tabla. Ya después, [...] en vez de ir a hacer otras cosas, prefería patinar con otros amigos". Sus amigos y sus padres recuperaron para él lo que la violencia y la calle le había arrebatado en la infancia: la lectura y los juegos. Y le hicieron sentir "esa sensación", que no sabe definir con precisión, pero que fue lo que lo llevó a dejar el mundo de la violencia y la muerte y a lanzarse de lleno a la construcción de una cultura de paz. 


\subsection{Vidas que optan por la humanización}

Ana, otra joven que compartió su historia de victimización, relató que a los seis años se hizo cargo de su hermano pequeño. "Yo le daba comida, yo lo bañaba, yo le cambiaba los diapers"27. A veces, las víctimas se convierten en vida para los demás. Vida nueva y alternativa. No está claro de dónde sacan el ánimo y las fuerzas, de dónde se agarran para ser vida para otros, pero, de hecho, lo son. Quizá no ponen signos espectaculares, ni hacen gestos grandiosos, pero tienen detalles muy significativos, que no pueden ni deben pasar desapercibidos.

Así, en medio del desastre más absoluto, Valeria, una mujer que ha sufrido un sinfín de violencias, amenazas y humillaciones, infligidas tanto por las pandillas como por el Estado, tiene capacidad para decir que es necesario transformar la fuerza personal en entrega a los demás. Ella no se deja arrastrar por el odio, que sería la solución más fácil. Poder expresar que la solución no es el odio, sino transformar la fuerza personal para ayudar a los otros, es un pequeño milagro de la vida, en medio del sinsentido.

Estas personas, dicho con palabras de Sobrino, viven la santidad primordial. En lo profundo de su ser, hay un deseo de querer vivir con los demás. Ese deseo es mayor, cuanto mayor es el desastre. Por eso, Sobrino afirma, sin faltar a la verdad, que "apareció la tragedia y el encanto de lo humano"28.

\subsection{Vidas por la empatía y contra el maniqueísmo}

Por último, las víctimas nos dan vida, cuando optan por la empatía y luchan contra el maniqueísmo. La empatía es la capacidad del ser humano para identificarse con alguien y compartir sus sentimientos. La empatía suele ir de la mano del conocimiento y del cariño. Cuando se conoce a alguien, es más sencillo acercarse a su dolor y su sufrimiento. Desde otra perspectiva, resulta más difícil causar sufrimiento y dolor a alguien que se conoce y se aprecia. Así lo expresa Érick, al relatar cómo unos jóvenes pandilleros se acercaron y dispararon contra su padrastro. "Después, llegaron otros tres, el cual uno de ellos era un compañero de escuela mío. Se me quedó viendo y agachó el rostro". Es la vergüenza de saber que se está haciendo algo incorrecto. En medio de la violencia, hay un rostro que se agacha y se esconde, porque reconoce que lo que se va a hacer solo lleva al fracaso y a la inhumanidad.

Las víctimas entrevistadas también son invitación a romper con el maniqueísmo. Valeria es hermana y esposa de pandilleros y defensora de los derechos de los presos, pero, al mismo tiempo, personalmente, está alejada de todo lo relacionado con provocar dolor y sufrimiento. Por eso, ella se ha convertido en

27. Diapers: pañales de tela no desechables.

28. J. Sobrino, "La santidad primordial", op. cit., p. 48. 
palabra autorizada que rompe el maniqueísmo prevaleciente, el cual considera que unos siempre son buenos y los otros siempre son malos.

William es un joven policía que participó activamente en una ejecución extrajudicial. Recuerda los momentos previos al asesinato de otro joven como él, relacionado con una pandilla. "Oír sus palabras... oír su voz. Yo siento que en esos cinco minutos que hablé con él yo lo conocí. Y para mí, esa persona ya no era lo que los demás compañeros decían". En medio de todo, aquel joven fue reconocido como persona, como interlocutor. William quebró el maniqueísmo y detrás de la etiqueta de "malo", descubrió a una persona, una historia, una vida.

Valeria y William, dos matices de una misma realidad, son invitación a romper con el maniqueísmo y con la corriente social que estigmatiza a una gran parte de la población como malvada sin remedio. Los dos se duelen por la muerte de pandilleros. Los dos los reconocen como violentos, porque lo son, pero también como víctimas de una sociedad injusta, que no ofrece ninguna solución.

La realidad es tan compleja, que no se puede caer, como advertía Ellacuría, "en una división maniquea del mundo, que pondría a un lado todo lo bueno, y al otro, todo lo malo" 29 . Las víctimas nos proyectan la complejidad de la realidad salvadoreña, donde los que son malos para unos, son buenos para otros y viceversa. $Y$ de esa manera, nos invitan a romper el estigma y a no juzgar y condenar tan fácilmente.

\section{Caminos de sanación}

No pretendemos presentar un proyecto completamente estructurado y concreto para conseguir la reconciliación en El Salvador. Tampoco buscamos una receta para construir la paz. Solo pretendemos reflejar las experiencias y las visiones de las víctimas y de su lucha permanente por superarse. Desde el escándalo de las distintas violencias y desde el dolor y la muerte, surge el camino para sanar y vivir. A continuación, presentamos algunas de esas necesidades.

\subsection{Ser escuchados y acogidos}

Antes de cualquier proceso de transformación personal o social, antes de hablar de reconciliación, de justicia y perdón, las víctimas tienen una necesidad elemental: ser escuchadas. Al ser escuchadas, las víctimas pueden exteriorizar el dolor que llevan dentro, poner en palabras el escándalo de su sufrimiento, denunciar las distintas opresiones a las que están sujetas y reflexionar sobre vías alternativas para recuperar su vida y su dignidad.

29. Cfr. I. Ellacuría, "El pueblo crucificado. Ensayo de soteriología histórica", en Escritos teológicos, vol. II, op. cit., p. 155. 
No se trata, sin embargo, de un mero ser oído. La escucha es un ejercicio activo, que exige un alto nivel de atención y de sensibilidad para el oyente. Escuchar es estar con la víctima y acogerla a ella y a su testimonio. Es abrazarla espiritualmente. En este sentido, ser escuchado tiene un potencial sanador.

Aunque ninguno de los entrevistados articula esta necesidad de manera explícita en las entrevistas, todos, sin excepción, la expresaron, en algún momento del proceso de investigación.

Las iglesias, por su misión cristiana y su presencia territorial, son estructuras idóneas para ofrecer espacios seguros y acogedores, donde las víctimas pueden ser escuchadas. Existen heridas que demandan de algo más que escucha. Todas las víctimas entrevistadas en esta investigación sufren traumas severos, que exigen ayuda psicológica profesional. Varios de los entrevistados son conscientes de esta necesidad y la mencionan explícitamente. Juan, por ejemplo, sufre trastornos a causa del encierro en el que vive, a raíz de su desplazamiento.

Uno siente un dolor a partir de la tristeza, la decepción que a uno le da cuando uno solo se va a aislar. Da depresión, porque uno, realmente, los problemas psicológicos los tiene. [...] Yo diría que para superarlo, uno necesita atención, primero psicológica, atención para superar el trauma que uno ha generado.

Cuando la ayuda psicológica no llega, la familia se convierte en apoyo fundamental para las víctimas, a pesar de la gravedad de sus padecimientos. El núcleo familiar, ya sea el padre, la madre, los hermanos, los hijos o los nietos, es lo que puede generar cierto sentimiento de seguridad en las víctimas. Cuando todo lo demás se derrumba, la familia aparece como el último refugio. Las familias, en muchos casos, se unen en las situaciones de sufrimiento y victimización y crean modalidades de solidaridad y amor excepcionales.

\subsection{La verdad que dignifica}

Las víctimas exigen verdad, saber la verdad sobre sus familiares desaparecidos o asesinados y hacer saber su verdad ante el mundo entero. Verdad como dignidad. La defensa de la verdad, según Sobrino, es una de las revelaciones principales del Dios de Jesucristo a la humanidad ${ }^{30}$. En su carta a los Romanos, Pablo encuentra palabras para expresarlo con claridad: "Desde el cielo nos amenaza la indignación de Dios por todas las maldades e injusticias de aquellos que sofocan

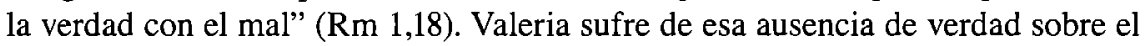
paradero de sus hermanos desaparecidos, la cual no la deja encontrar paz: "Saber qué pasó, saber dónde están. Eso ayudaría mucho, porque ya uno como que se va sintiendo más tranquilo".

30. Cfr. J. Sobrino, "El cristianismo y la reconciliación. Camino a una utopía", Concilium 303 (2003), 98. 
La verdad, aquí, consiste en algo más que palabras. Está muy vinculada a la justicia. La verdad es afirmación de la vida y, como tal, vida misma. Además, la verdad se opone a la mentira, que es injusticia, muerte y, por tanto, pecado. La falta de la verdad, o la mentira institucionalizada, es, como se ha expuesto antes, uno de los factores determinantes de los niveles de deshumanización y violencia actuales. La verdad es liberadora ( $c f r$. Jn 8,32). Para Kevin, la verdad está intrínsecamente vinculada a la justicia: "Que se dé a conocer la verdad de lo que está pasando. Para mí, eso sería un ejemplo de cómo hacer justicia. Que se sepa la verdad". Aída comparte esta visión.

La justicia es verdad. Si tú actúas de una manera adecuada, dices siempre la verdad, haces las cosas bien, entonces estás haciendo justicia, porque no te podés poner a decir "esto es justicia" y estás haciendo las cosas contrarias, estás mintiendo, estás delinquiendo o estás maltratando a los demás.

Este potencial liberador que tiene la verdad no puede quedarse en la esfera personal. Varios entrevistados señalan que adquirir conciencia y saber la verdad sobre lo que está ocurriendo en el país, aparte de dignificar y ayudar en los procesos personales de sanación, es la base para una posible transformación de la realidad. Según Aída, conocer y reconocer la verdad de las víctimas "en lo personal y tanto familiar [...] ayudaría mucho. También, quizás, a nivel de país, porque si [...] se están aclarando las cosas, quizás, podría girar o encaminarse a un futuro mejor nuestro país". Luego, agrega:

Que se sepa lo que pasa y, pues, para que todas las personas que han sido víctimas puedan hablar, que pierdan el temor [...] que sepan de que existe un lugar donde puedan llegar, les pueden atender y les puedan ayudar, sin temor a que puedan $[s i c]$ haber consecuencias.

"Hay que sacar a la gente de la ignorancia", exclama Valeria, haciendo referencia a lo mismo. Si en El Salvador al menos se lograra satisfacer esta primera necesidad de las víctimas, la de ser reconocidas y la de escuchar y aclarar su verdad, se daría un gran paso hacia la humanización. Pero la verdad implica la responsabilidad y la acción transformadora. Por esa razón, en la actualidad, ni siquiera ese mínimo de dignidad se concede a las víctimas.

\subsection{Justicia y restauración}

Una vez conocida la verdad de las víctimas, es necesario hacer justicia. La verdad deja al descubierto sus heridas, las expone a la vergüenza pública y las hace aún más vulnerables. La justicia cierra esas heridas, porque sana y repara.

Varios entrevistados consideran la cárcel como el castigo adecuado para los victimarios. Juan, víctima de amenazas y desplazamiento, dice lo siguiente: "Sería bueno que pagarían a prisión, una condena, me gustaría por muchos años, para que ellos reconocieran de que lo que han hecho es malo". Dos voces de 
entre los entrevistados demandan medidas más extremas, como, por ejemplo, la pena de muerte o el exterminio de los pandilleros. Esto es así y es necesario oír esas voces. Sin embargo, la gran mayoría de las víctimas entrevistadas buscan una justicia que va más allá de la lógica del castigo. Sin referirse a concepto determinado, ellas imaginan y anhelan una justicia que reconoce, restituye, rehabilita y restaura.

Aparte de oponerse a la violencia, entre los entrevistados se observa una conciencia muy grande de que la violencia es un problema social y que el fenómeno de las pandillas es producto del fracaso de la sociedad y del Estado. Por eso, para ellas, hacer justicia va más allá de la dimensión individual e incluye la rehabilitación de los victimarios. Émerson, un joven de veintidós años, cuyo padre fue asesinado por pandilleros, dice:

Todos tenemos una oportunidad más, pero si no se les ayuda, ellos van a volver a lo mismo, prácticamente. Habría que ayudarles con oportunidades de estudio. Tratar de involucrarlos poco a poco en la sociedad, para que ellos no vuelvan a caer en lo mismo.

Estos y otros testimonios no son necesariamente expresiones de compasión para con los victimarios, ni mucho menos intentan disculpar los hechos de violencia, que las víctimas todavía expresan con mucho dolor por los daños sufridos. La propuesta de rehabilitar y reinsertar al victimario, desde la perspectiva de la víctima, tiene claramente el propósito de restaurar el tejido social y de evitar que sus victimarios hagan daño a otras personas.

En este sentido, la justicia que anhelan las víctimas no busca la venganza, sino la garantía de la no repetición. Su postura está más en sintonía con el concepto de justicia restaurativa que con el sistema tradicional de justicia penal y retributiva. La justicia restaurativa coloca a la víctima y sus necesidades en el centro y busca restaurar las relaciones sociales, tanto entre la víctima y el victimario como en la sociedad en su conjunto. Partir de las necesidades de las víctimas e integrar elementos restaurativos en la concepción de la justicia es un reto urgente para el sistema judicial de El Salvador.

\subsection{La necesidad de perdonar}

Indudablemente, el perdón es el paso más delicado y difícil del proceso de reconciliación. Según Sobrino, el que ofrece perdón, en última instancia, renuncia radicalmente a derechos legítimos y se olvida totalmente de sí mismo por amor al prójimo". El perdón "no se puede manipular" ${ }^{32}$. El perdón no se

31. Cfr. J. Sobrino, "La redención de la violencia", Concilium 4 (1997), 101.

32. Ibidem: 
impone. Aun así, el perdón es parte indispensable de todo proceso de verdadera reconciliación.

Para María, el perdón está directamente relacionado con la posibilidad de volver a vivir en paz: "Si nosotros no perdonamos, vamos con esto que nos mata que es el odio. El odio nos destruye y si nosotros no perdonamos, pues no tenemos paz". Perdón, para los entrevistados, de ninguna manera significa olvidar o reprimir el daño sufrido. Al contrario, perdonar es reconocer y liberarse así de la carga del odio y del dolor.

Asimismo, varias víctimas entrevistadas subrayan que el perdón, primariamente, es una necesidad de la víctima y no implica ningún acercamiento al victimario, y más bien, requiere de distancia y de tiempo.

\subsection{Empatía, diálogo integral y transformación social}

Las víctimas no se desentienden de la dimensión interpersonal y social. De hecho, esta las impulsa a la reconciliación. Están convencidas de que solo la empatía, la apertura al otro, la conciencia y el diálogo pueden contrarrestar la violencia y fundamentar la construcción de algo nuevo. Desde su propia experiencia de victimización, lanzan esta necesidad como desafío a la sociedad.

Ana, para quien el estigma más grande de su vida es haber nacido y crecido en un contexto sumamente pobre, con las discriminaciones que esta realidad conlleva, hace un llamado a la empatía, a interesarse en el otro y a no discriminar.

Sentirse en los zapatos del otro... [...] A veces, necesitamos que esté alguien y nos diga "sí", que nos apoye [...] considero de que la empatía y la sensibilidad por el prójimo juega un papel muy importante. [...] No tengo que discriminar a nadie y creo que ese es el problema aquí en nuestro país. [...] Si no hay empatía, pues siempre va a haber una desigualdad, tanto cultural, social y emocional.

Valeria habla de la necesidad de un proceso a nivel nacional, que incluya a toda la sociedad, para realizar lo que ella llama una cultura de diálogo.

[Habría que] dialogar con las partes adecuadas, [...] hablar, digamos, desde arriba para abajo y de abajo para arriba, para hacerle conciencia a la gente que son diferentes enfoques de problemas y no es un solo enfoque de odio.

Más que un diálogo político o una negociación de intereses, los entrevistados proponen abrir espacio a una verdadera empatía. Solicitan empezar a escucharse mutuamente y a buscar soluciones en conjunto para introducir las transformaciones sociales que el país tanto necesita. 
William, un agente de la policía, diariamente se enfrenta con una guerra cruel, que percibe como absurda. Cree que en lugar de enfrentarse con armas en los pasajes y los maizales, policías y pandilleros deberían sentarse a hablar.

Sentar a un pandillero y un policía enfrente, que los dos expresen: "¿Por qué lo hacés? ¿Por qué el odio hacia mí?". Salir de dudas y entender. Detrás de esa faceta, de esas profesiones que tenemos, hay dos personas civiles, que piensan, que sueñan, que desean, y creo que podría haber entendimiento, pero aclarando todo, hablando con la verdad.

\section{Conclusiones}

Las víctimas no permanecen calladas. Si bien están acorraladas por sus victimarios, las pandillas, el Estado o incluso sus propios familiares, y si bien han sido silenciadas por la sociedad, su clamor por la vida llega al cielo y resuena en la humanidad. Cada una de ellas, desde su dolor y su lucha diaria, construye, piensa y sostiene otro mundo más justo y más humano.

La exigencia primera y principal de las víctimas es ser escuchadas. Solicitan espacios y personas que las acojan cuando lo necesiten. Luego, exigen verdad, saber la verdad respecto a sus familiares desaparecidos o asesinados y hacer saber su verdad ante el mundo. Verdad como dignidad. Exigen justicia, una justicia expiatoria, pero sobre todo, una justicia restauradora e integral, que garantice que nunca nadie vuelva a pasar por lo que ellas han pasado. Las víctimas necesitan perdonar para encontrar su paz y volver a la vida. Por eso, emprenden el largo y doloroso camino de aprender a perdonar. Las víctimas buscan y promueven la empatía y el diálogo, porque, para ellas, esta es la única manera de superar el odio y la violencia. Y, finalmente, trabajan, cada una desde su espacio y su caminar, por la transformación y la humanización de la sociedad.

Son los últimos, los "curtido[s] en el dolor" (Is 53,3), los históricamente crucificados, quienes van por delante, anunciando el reino y salvando a la humanidad. Ellos nos invitan y nos llaman a acogerlos y a seguirlos hasta el final. 